\title{
Represión a la izquierda en la provincia argentina de Entre Ríos durante la Revolución de Junio, 1943-1945
} Repression left in the Argentine province of Entre Ríos during the Revolution
of June, 1943-1945

\author{
Rodolfo Leyes*
}

\begin{abstract}
Resumen
Este trabajo muestra la represión que desarrolló la denominada "Revolución de Junio" desde 1943 hasta 1945. Dicha investigación tiene valor por su aporte a la historia del peronismo, pero también, y sobre todo, la reconstrucción de la coacción sobre el movimiento obrero, la izquierda y aquellos que el régimen dictatorial consideró fuera de su concepción del orden. Otra particularidad del estudio es que está asentado en la provincia argentina de Entre Ríos, cuando la mayoría de los estudios se centran en la Capital Federal y su conurbano.
\end{abstract}

Palabras clave: Represión, Izquierda, Movimiento obrero, Peronismo, Entre Ríos.

\begin{abstract}
This work shows the repression implemented by the "June Revolution" from 1943 to 1945 . This research is good at contributing to the history of peronism, but also, and especially, to the reconstruction of the coercitive process against labour movement, left-wing and those who were considered out of dictatorial regime's conception of order. Another distinctive feature of this study is that it's settled in Argentinean province of Entre Ríos, while most of other studies are settled in Buenos Aires and its metropolitan area.
\end{abstract}

Keywords: Repression, Left, Labour Movement, Peronism, Entre Ríos

Recibido: 19 septiembre 2016

Aceptado: 4 diciembre 2016

\footnotetext{
* Argentino, Becario doctoral. UADER/CONICET, Proyecto de tesis: Título: El surgimiento del peronismo y las corrientes obreras sindicales en Entre Ríos (1932-1947)" (2013-2018). Rodolfoleyes@yahoo.com.ar
} 
La política y las ideologías extrañas que suelen ensombrecer a las masa son como bombas de tiempo, listas para estallar y llevar la destrucción al gremio, que no debe ocuparse de cuestiones ajenas a sus intereses y a sus necesidades.

Discurso del Coronel Perón a los trabajadores de Concepción del Uruguay 25 de junio de $1944^{1}$

\section{Introducción}

Una de las primeras preguntas que todo historiador del movimiento obrero argentino se hace es ¿cómo el peronismo se convirtió en la corriente política dominante dentro del mismo? Las respuestas, dispares y variadas, nos llevan a que, aún hoy, después de medio siglo, exista una pluralidad de posibles explicaciones del fenómeno en general y de su internalización en las masas obreras en particular.

La construcción de todo nuevo orden político, que reemplace el que estaba en el poder, se hace a partir de dos elementos fundantes. El primero es la coerción, la violencia física sobre los sujetos sociales opuestos al nuevo régimen en formación. El régimen en ascenso intentará destruir a los líderes opositores, pero fundamentalmente, ganarse a las masas que le sirven de base. Para ello, Concede parte de los reclamos obreros en pos de contenerlos dentro del régimen. Así, la violencia, está acompañada del consenso necesario de las masas. Coerción y consenso, violencia y beneficios, llevan a que un nuevo poder se yerga sobre una situación determinada. ${ }^{2}$

El golpe de estado de 1943 se produjo en un contexto donde el ostracismo alcanzaba al último presidente del régimen conservador y habilitaba cierto consenso inicial al derrocamiento, lo que trae a escena al Ejército como factor decisivo. Dentro de los planes de los coroneles responsables del golpe, existía desde su mismo origen, la idea de combatir a la izquierda. La plataforma política proyectada por los uniformados, no podía ser otra que

\footnotetext{
${ }^{1}$ Perón, Juan Domingo: “A los trabajadores de Concepción del Uruguay” en Obras Completas, Buenos Aires, Fundación proUniversidad de la Producción y del Trabajo, Tomo 6, 1997, p.212.

${ }^{2}$ Gramsci, Antonio: Notas sobre Maquiavelo, sobre la política y sobre el Estado moderno, Buenos Aires, Ed. Nueva Visión, 2003, p.147.
} 
la reconciliación "de los argentinos", para ello, destruir a las ideas disolventes y "extranjerizantes" era una necesidad.

La represión desatada contra las organizaciones obreras, la clausura de los partidos políticos, intervención de los sindicatos y encarcelamiento de militantes, en los primeros días de julio de 1943, llevó a que el movimiento obrero, que en un primer momento aplaudía el golpe de estado, a tomar distancia del gobierno revolucionario. Por los avatares de la política interna, la posición agresiva de los dirigentes obreros, fue dando paso a una distención por el lado obrero, y a una selección de la represión, con la intensión de ganar adeptos por parte de los militares.

Mientras tanto, el gobierno emprendía el desarrollo de la política social, brindando apoyo a unos dirigentes en detrimento de otros, haciendo que los más reacios, o se sumaran al proyecto gubernamental o dieran un paso al costado. Esta política, de atacar a los dirigentes y, en paralelo, otorgar beneficios a las masas para, finalmente, construir un grupo de líderes que, con sus reservas, servían como correa de transmisión de la Secretaria de Trabajo y Previsión, fueron los que tendieron el puente entre Perón y las masas de trabajadores. ${ }^{3}$ Este fue el proceso político-social necesario para construir la vinculación política que salvó a Perón en los acalorados días de octubre de 1945.

El proceso represivo de la revolución de Junio y el ascenso de Perón, ha sido paso obligado para los estudiosos del proceso peronista en su nacimiento, y en buena medida, lo dicho se refiere a Buenos Aires y su conurbano. Este trabajo, que pertenece a un proyecto más amplio, pretende mostrar como el proceso descrito más arriba se manifestó en la provincia de Entre Ríos, reconocer a los sujetos implicados y ofrecer una reconstrucción histórica que nos permita constatar la hipótesis de los mecanismos coercitivos como prácticas necesarias para la construcción de una nueva vinculación política.

\section{1-La naturaleza ¿represiva? del peronismo.}

En los primeros días de la revolución de julio se dieron en casi todo el país una serie de acciones represivas contra los miembros de los partidos de izquierda y dirigentes del movimiento obrero organizado. Estos sucesos hicieron que las organizaciones golpeadas y parte de la opinión pública en general se pusieran en guardia y alerta frente a lo que se definió como "nazi-fascismo". La mancha de aquellas jornadas fue para muchos indeleble e imperdonable. Perón, como heredero de esa revolución, recibió buena parte de la responsabilidad sobre los hechos y ha dado lugar a enconados debates en torno a su responsabilidad personal.

\footnotetext{
${ }^{3}$ Torre, Juan Carlos: La vieja guardia sindical y Perón, Buenos Aires, Ediciones RyR, 2011. Y Matsushita, Hiroshi: Movimiento obrero argentino, 1930-1945, Buenos Aires, Ediciones RyR, 2014.
} 
Casi todos los estudios sobre el fenómeno peronista en sus comienzos, repasan estos hechos con mayor o menor detalle. Las corrientes se podrían dividir entre los que ven la represión como parte de un proceso de integración, donde el programa totalitario media entre lo que debe ser la participación, las ideas aceptadas y las prácticas permitidas de las que no. En alguna medida, el lado "totalitario" de los gobiernos "nacional-populares" saldría a la superficie con estas acciones, de allí el apelativo de "fascista". Así es que Germani se refirió al peronismo como un tipo de fascismo o gobierno totalitario con rasgos particulares, por la configuración político-económica del país, nutrida por una base social de migrantes internos que funcionaron como masas disponibles, sin cultura democrática y urbana, a cambio de la integración comandada por la figura carismática de Perón. ${ }^{4}$ Fayt, por su parte, afirmó que los partidos "democráticos" habían logrado reconocer los caracteres fascistas del gobierno revolucionario, pero no los cambios hacia el populismo a partir de 1945. Sin embargo, insiste en que se ejerció un efecto de pinzas sobre el movimiento obrero había servido para dar como resultado el apoyo a Perón y la espalda a las organizaciones de izquierda. ${ }^{5}$ También José Luis Romero se inclinaba por marcar una continuidad entre el golpe del `43 y la obra de Perón, a quién no dudaba en tildar como nazi: "era evidente que el propósito era reducir la vida cívica del país hasta sus límites extremos, y encuadrarlos dentro de férreos marcos militares”, en tanto, el G.O.U. sería un grupo comprometido con la infiltración nazi en el país. ${ }^{6}$

Estos tres autores pueden ser muestras y variantes de un discurso histórico, que tiene por común la visión totalitaria, fascista del gobierno del GOU y lo hacen extensivo al de Perón (1946-1955). Los autores además son contemporáneos de los hechos relatados. También son representantes de la conciencia liberal, democrática o republicana, lo que permea toda la reconstrucción histórica.

Autores como Louis Doyon, Joel Horowitz, Hugo Del Campo, Hiroshi Matsushita y Juan Carlos Torres, interpretaron al fenómeno represivo como medidas tendientes a la construcción del poder gubernamental. Sería, por lo tanto, un proceso específico y limitado a un momento dado de las relaciones de fuerzas. Doyon se limita a explicar las represiones de junio-julio de 1943 como parte de un viraje a la derecha del gobierno. ${ }^{7}$ Algo similar sucede con Del Campo y Horowitz, que se detienen en la represión de los comunistas por

\footnotetext{
${ }^{4}$ Germani, Gino: Política y sociedad en una época de transición, Buenos Aires, Paidos, 1962, pp. 231-252. ${ }^{5}$ Fayt, Carlos: La Naturaleza del peronismo, Buenos Aires, Viracocha, 1967, p. 107.

${ }^{6}$ Romero, José Luis: Las ideas políticas en Argentina, Buenos Aires, FCE, 2005, p. 250. [Primera edición 1956]

${ }^{7}$ Doyon, Louis: Perón y los trabajadores: los orígenes del sindicalismo peronista, 1943-1955, Buenos Aires, Siglo XXI editores, 2006, p.100.
} 
esos mismos meses, el decreto de disolución de la CGT No $2,{ }^{8}$ la nueva ley de asociaciones gremiales que buscaba la disociación de la política partidaria y las actividades gremiales, así como la clausura de sindicatos y la intervención de la Unión Ferroviaria. ${ }^{9}$ En el caso de Matsushita, quién por lo menos tiene la intención de mencionar la represión en el interior, agrega que la represión duró hasta octubre, cuando las autoridades del golpe decidieron un cambio en la relación con el movimiento obrero - no así con la izquierda en su conjunto- y se ubicó al Coronel Perón en el Departamento Nacional de Trabajo, el 27 de octubre de 1943. ${ }^{10}$ En el caso de Juan Carlos Torre, nos encontramos con una explicación que busca superar la descripción de los hechos, para agregar que la represión de los comunistas fue necesaria para el desarrollo de la "justicia social", a esto, el autor lo llama "política dual". 11

En la discusión sobre el carácter represivo del peronismo se ha escrito mucho, en general, en el ángulo de los estudios previos y que han sido referenciados más atrás. Sin embargo, actualmente fue publicado un trabajo novedoso, obra de Marina Kabat que muestra con nuevas fuentes -algunas pertenecen al repositorio que utilizamos para el presente trabajo- y ubican al peronismo como un "Bonapartismo policíaco" siguiendo a Gramsci. ${ }^{12}$ En efecto,

En el marco estrictamente provincial, los estudios relacionados al mundo del trabajo, en particular a las experiencias de la Federación Obrera Comarcal (FOC) de tendencia anarquista de Diamante y la Unión Obrera Departamental (UOD) de tendencia sindicalista de Concepción del Uruguay, han relatado los hechos represivos a los que fueron sometidos los dirigentes y las organizaciones, acusados de "portación de ideas extranjerizantes". Para el caso de la experiencia libertaria, dado que la FOC se encontraba casi destruida, con solo algunos de sus antiguos sindicatos aún operativos, su análisis ha sido pasado por alto. En tanto, para el caso de la UOD, los dos estudios que disponemos a la fecha, los de María del Carmen Arnaiz y de Elisa Balsechi y Jorge Gilbert, mencionan el hecho del encarcelamiento de su máximo dirigente, Juan Balsechi, sobre el que nos referiremos más adelante a partir de nuevo material probatorio. ${ }^{13}$ Estos autores se enmarcan dentro del grupo

${ }^{8}$ La CGT se había divido en dos organizaciones por un conflicto en las elecciones realizadas en marzo de 1943, y tomaron los nombres de acuerdo al número de su lista, la $\mathrm{N}^{\circ} 1$ de los socialistas y la $\mathrm{N}^{\circ} 2$ de $\operatorname{los}$ comunistas. Ver: Matsushita, 2014: 333-343.

${ }^{9}$ Horowitz, Joel: Los sindicatos, el Estado y el surgimiento de Perón, 1930-1946, Buenos Aires, Universidad Nacional de Tres de Febrero, 2004, p. 260-261. Y Del Campo, Hugo: Sindicalismo y peronismo, Buenos

Aires, Siglo XXI Editores, 2005, p.180-184.

${ }^{10}$ Matsushita, Op. cit., pp. 347-360.

${ }^{11}$ Torre, Op.cit., pp. 80-91.

${ }^{12}$ Kabat, Marina: "El peronismo, los orígenes de la SIDE y de la 'maldita policía'” en Razón y Revolución, Segunda Época, N 29 , 1er. Trimestre, Buenos Aires, pp.112-114.

${ }^{13}$ Arnaiz, María del Carmen: "Un Oasis en el desierto. La Unión Obrera Departamental de Concepción del Uruguay" en Di Tella, Torcuato: Sindicatos como los de antes... Buenos Aires, Biblos, 1993, p.110. Y Gilbert, 
de quienes entienden la represión como hecho coyuntural propio del juego de poderes que desarrollaba el grupo de uniformados en el golpe del ` 43.

Un déficit de ambos tipos de análisis, es ponderar la situación represiva o la coyuntura de represión como instancias contradictorias. En este sentido, omiten que es el proyecto de todo gobierno burgués, sea militar o civil, buscar la despolitización de la clase trabajadora o bien, la subordinación de ésta a los partidos del orden social establecido. Por lo tanto, la necesidad estratégico-política de reprimir va de la mano de un proceso de disciplinamiento social sobre la clase obrera, que responde a los intereses primarios de la burguesía. Que el caso de estudio derive hacía un gobierno de corte bonapartista, ${ }^{14}$ no lo hace menos burgués, sino lo contrario. Se acentúa la naturaleza de clase del Estado, que intenta ordenar las pugnas entre las clases antagónicas, y si la represión alcanza a fracciones burguesas, no es por los "imaginarios totalitarios", sino porque estos no se quieren plegar a su propio Estado, lo que pone en peligro a todo el orden social.

Por nuestra parte creemos que primero se debe enmarcar la lógica represiva común a cualquier Estado, y el hecho de que sea un golpe militar es lo que le da carácter particular, ya que los uniformados deberán acelerar el proceso de formación de una hegemonía para poder desarrollar sus objetivos políticos. En segundo lugar, no se puede concluir una "naturaleza" inmanente al gobierno dictatorial o al peronismo, sino mediada por la búsqueda de la construcción del poder gubernamental. Mucho menos, se puede hacer extensiva la represión a los trabajadores dentro del peronismo como un elemento intrínseco al gobierno comandado por Juan Domingo Perón, sino su uso alternado con los beneficios secundarios para la clase obrera, es decir, la represión como necesidad, como política por otros medios.

\section{2-La revolución de junio, la izquierda y la intervención de Entre Ríos.}

La revolución de junio de 1943 estuvo encabezada por un grupo de oficiales, reunidos en torno a una logia militar llamada Grupo de Oficiales Unidos o Grupo de Obra Unificada

Isidoro \& Balsechi, Elisa: Voces del sindicalismo entrerriano: Memorias de la Unión Obrera Departamental de Concepción del Uruguay, 1918-1943, Buenos Aires, Ediciones del Zorrito, 2008, p.100.

${ }^{14}$ El concepto de Bonapartismo, acuñado por Marx para explicar el gobierno de Luis Bonaparte, se utiliza para conceptualizar a los gobiernos que aparentan operar por encima de las diferencias de las clases sociales, otorgando concesiones y castigos dependiendo de la construcción política en la coyuntura, como forma de preservar el orden establecido. El surgimiento de los bonapartismos se dan en momentos que la lucha de clases amenaza el sistema, o bien son necesarias transformaciones que por la propia puja de intereses, por el empate en la relación de fuerzas, no se pueden dar sin la presencia activa del Estado. Ver: Marx, Carlos: "El dieciocho brumario de Luis Bonaparte" en Marx, Carlos \& Engels, Federico: Obras escogidas en dos tomos, Moscú, Editorial Progreso, 1955, Tomo I. 
(GOU). Los militares del GOU, hacían especial hincapié en la lucha contra el comunismo, aunque claramente sus objetivos excedían ello. ${ }^{15}$ Así, en su "G.O.U. Bases. Plan de Unificación" - para algunos autores, escrito por el mismísimo Perón- ${ }^{16}$ se hablaba de la situación nacional que:

Frente a la concentración y unificación de las fuerzas políticas adversas al orden establecido se tiene una dispersión y división de fuerzas de orden. Con ello se corre el mayor peligro en los comicios, como en la lucha que puede resultar como consecuencia de ellos. La inseguridad política puede llevar, en plazo más o menos corto, a una de las siguientes situaciones:

-Triunfo de las tendencias actuales y refirmación (Sic) de la orientación actual en política internacional;

-Triunfo de las tendencias actuales, pero con el cambio de la actual política internacional y como consecuencia el estado de guerra;

-Triunfo del "Frente popular", disfrazado, como Unión Democrática, que busque inmediatamente, o en forma inmediata, la revolución comunista (caso de España o Chile). ${ }^{17}$

El discurso de los militares, buscaba mantener la neutralidad frente a la guerra mundial y, a la par, de no perder de vista a un enemigo calificado como comunista. Tales eran los fundamentos de la acción política de la futura intervención. Por eso declaraban en sus Bases de Acción que:

En el orden político interno pensamos que no pueden llegar al Gobierno del país las fuerzas comunistas o las asociadas con ellas en cualquier forma. El Frente Popular debe ser destruido antes de su éxito político o durante el mismo, para evitar la guerra civil, que tampoco tememos, pero que estamos en la obligación patriótica de evitarla. ${ }^{18}$

La influencia de la Guerra Civil española había permeado la vida de muchos países latinoamericanos. Aquí, el léxico utilizado, demuestra las conclusiones sacadas por los uniformados. También en las disposiciones prácticas para los miembros del G.O.U., la

\footnotetext{
${ }^{15}$ Campione, Daniel: Orígenes estatales del peronismo, Buenos Aires, Miño y Dávila, 2007, p.27.

${ }^{16}$ Mier, Eugenio: "Nota aclaratoria" Perón, Juan Domingo: en Obras Completas, Buenos Aires, Fundación proUniversidad de la Producción y del Trabajo, 1997, Tomo 6, pp.23-25. Y Potash, Robert: El ejército y la política en la Argentina, Buenos Aires, Hyspamerica, 1985, Tomo I, p. 266-277.

${ }^{17}$ Potash, idídem, pp. 27-28.

${ }^{18}$ Potash, Robert: Perón y el G.O.U. Los documentos de una Logia Secreta, Buenos Aires, Editorial Sudamericana, 198, p. 30. Dentro de uno de los documentos rescatado por Potash, con el membrete de "Estrictamente confidencial y secreto" se habla de la situación interna del país, comparando directamente a la Unión Democrática con el caso español: "Se trata de una agrupación netamente revolucionaria que pretende reeditar el panorama rojo de España, donde las fuerzas moderadas caen finalmente, para ser instrumentos de los comunistas.”, Ibídem, p.199.
} 
lucha contra el comunismo estaba entre sus tareas, en especial contra el trabajo de propaganda producido por los comunistas sobre los suboficiales y la tropa, usando como ejemplo el caso español. Se proponía la creación de un servicio secreto del ejército para combatir la disidencia interna. ${ }^{19}$

En todos los casos, se reconocía que la existencia de la militancia izquierdista era producto de las malas condiciones de los obreros. Suponemos que los militares, conocidos promotores de la industrialización estratégica del país, pensarían que la mayor oferta de trabajo bastaría para la mejora de las condiciones objetivas de los trabajadores. A poco de producirse la toma del poder, comienzan a desarrollar políticas en los dos sentidos ya citados, por un lado, la represión de los individuos e instituciones sindicadas como izquierdistas, y por otro lado, la toma de medidas de orden social.

Para poder llevar adelante las políticas proyectadas, el gobierno golpista tuvo que desplazar a los políticos elegidos por el voto, y desplegar por las provincias intervenciones federales, es decir, personal político-militar de confianza, formado por los cuadros del G.O.U. La provincia de Entre Ríos sufrió la intervención el día 11 de junio. El jefe de la 3era. División del Ejército con asiento en Paraná, General Juan Carlos Sanguinetti, se hizo cargo interinamente del gobierno de la provincia, después de una "resistencia simbólica" del Gobernador Mihura. Algunos de sus ministros y simpatizantes que, encerrados dentro de la Casa Gris -edificio del poder ejecutivo provincial- esperaron a los militares cantando el Himno nacional. ${ }^{20}$

El 21 de junio fue relevado por el hermano del General Pedro Ramírez, el Coronel Ernesto Ramírez, ambos entrerrianos. Otros dos militares que se ocuparon de la intervención fueron: el Coronel retirado Carlos María Zavalla, desde el 4 de abril de 1944 hasta septiembre de ese mismo año, reemplazado por un oficial cercano a Perón, el General Humberto Sosa Molina. Finalmente, después de los sucesos de octubre de 1945 hasta las elecciones de 1946, Eduardo Francheri López. ${ }^{21}$

Durante los casi tres años de intervención se produjeron rebajas en los precios de los alquileres, control de los precios de las mercaderías, incluido el salario a pagar durante la cosecha, intentos de industrialización, el Estatuto del Peón rural, la expropiación de las usinas eléctricas en mayo de 1944, ayudas económicas a los colonos, etc. ${ }^{22}$

\footnotetext{
${ }^{19}$ Ibíd., p. 40.

${ }^{20}$ Periódico Actualidad, Nogoyá, 14/06/1943. Reula Filiberto: Historia de Entre Ríos, Santa Fe, Ed. Castellví, 1971, Tomo III, p. 113.

${ }^{21}$ Gianello, Leoncio: Historia de Entre Ríos (1520-1910), Paraná, Ministerio de Educación, 1951, pp. 556557.

${ }^{22}$ Diario La Acción, Paraná, 15/06/1943. Periódico El Entre Ríos, Colón, 16/11/1943, 27/11/1943, 21/10/1944 y 20/05/1944, Diario La Juventud, Concepción del Uruguay, 23/01/1945.
} 


\section{3-La represión a la izquierda.}

De la mano de la intervención vino la represión. Las medidas alcanzaron tanto hombres como instituciones. Pero hubo alguien que por el momento es el primer registrado en caer en manos de la policía. El histórico militante de la Unión Obrera Departamental de Concepción del Uruguay, Juan Balsechi. ${ }^{23}$ En efecto, el día 20 de junio de 1943, el General de Brigada Juan Carlos Sanguinetti informaba al Ministro de Ministro del Interior:

Poder Ejecutivo de la Provincia de Entre Ríos

Paraná, 20 de junio de 1943.

Al Señor Ministro del Interior

Coronel D. ALBERTO GILBERT

Tengo el agrado de dirigirme a V.E. poniendo en su conocimiento que desde el día de la fecha, se encuentra alojado en el Departamento de Policía de la Capital Federal, el dirigente Comunista Extremista JUAN BALSECHI (a) el manco Balsechi, cuyos antecedentes obran en la citada repartición. $^{24}$

Mientras sus compañeros pidieron una entrevista con el Intendente interventor de la ciudad de Concepción del Uruguay, para discutir el encarcelamiento, recibieron de este la noticia de que se gestionaría su liberación. Los sindicalistas decían "serenidad y cordura es la consigna", en un acto que había convocado a unos 800 trabajadores para conocer los informes. ${ }^{25}$ En tanto, pocos días después, se publicó un decreto que prohibía las actividades comunistas prestando particular atención a las instituciones que servían de usina y fachada para la propaganda comunista. ${ }^{26}$

Fueron cerrados los locales de organizaciones vinculadas al apoyo de los aliados de la Segunda Guerra mundial. Se clausuró en Paraná: Italia Libre, Junta de la Victoria,

\footnotetext{
${ }^{23}$ Juan Balsechi comenzó su militancia sindical durante el ciclo de luchas de 1917-1921. Miembro del sindicato de panaderos, de extracción sindicalista revolucionaria, desarrolló junto a otros militantes, en especial de la Federación Obrera Marítima, un complejo sindical-cooperativo, que se mantuvo por años como usina de las prácticas sindicales en la provincia, llamando muchas veces a su localidad "Capital del sindicalismo" por su actividad. A ese grupo militante se les debe buena parte de la formación de los sindicatos en la década del `30 y la obra de la Unión Obrera de la Provincia de Entre Ríos (UOPER). Lo apodaban "El manco" por haber perdido un brazo en un atentado en su contra producido por un carnero. Se puede consultar: Arnaiz, 1993, y Gilbert \& Balsechi, 2008.

${ }^{24}$ Telegrama del Interventor Federal Interino, General de Brigada Juan Carlos Sanguinetti al Ministro del Interior, Coronel Alberto Gilbert, Paraná, 20/06/1943 en Argentina-Archivo General de la Nación. Departamento Archivo Intermedio, Ministerio del Interior, Comisión de Organización de Archivos. Secretos, confidenciales y reservados, Caja No7, Documento Reservado 82. En adelante: Ar-AGN. DAI. MI. COA. SCR.CAJA N ${ }^{\circ}$, DOC.

${ }^{25}$ Periódico Unión Sindical, Buenos Aires, 30/06/1943.

${ }^{26}$ El Entre Ríos, 13/07/1943.
} 
Confederación Democrática Argentina y Comité Femenino de Ayuda a los Aliados, además los sindicatos de Panaderos, de obreros de la madera, de la construcción y sindicatos de obreros gráficos. Se informaba que habían encontrado ropas obtenidas mediante colectas y que ahora serían repartidas entre la gente pobre de la capital provincial. ${ }^{27}$ Días más tardes, en la ciudad de Gualeguay, se apresó a tres comunistas y se les decomisó de sus casas panfletos y documentos que los vinculaban con el Partido Comunista. A raíz de los documentos decomisados se dio a la tarea de apresar a otras veintiséis personas de la misma ciudad. Todos fueron conducidos a Paraná. ${ }^{28}$ También en La Paz, dónde se había formado un Comité de Ayuda a los aliados, constituido por miembros del partido comunista, radicales, demo-progresistas, socialistas y hasta algunos conservadores fue disuelto y un médico comunista, Antonio Santich, expulsado del hospital local. ${ }^{29}$

A mediados de agosto, la primera oleada represiva hacía su balance, en una publicación hecha por la Jefatura de Policía de Paraná, en la cual se informaba:

La División de Investigaciones de la Policía de esta ciudad, ha proseguido eficazmente con las actuaciones instruidas contra las actividades comunistas que venían desarrollándose hace mucho tiempo dentro de los principales centros poblados del territorio de la provincia. La investigación practicada ha dado por resultado establecer la instalación de centros del partido comunista en las localidades de Paraná, Basavilbaso, Domínguez, Gualeguaychú, Concordia, Gualeguay y Rosario Tala, los cuales fueron clausurados, incautándose de un nutrido material oral, gráfico, extremista, habiéndose procedido a la detención de numerosos individuos complicados en esta clase de actividades tendenciosos (...) El voluminoso expediente que se ha formado, agrega comprobaciones en las que aparece estrechamente vinculados con estos elementos partidos políticos como así también algunos de sus principales dirigentes... ${ }^{30}$

La información continuaba con la denuncia sobre las organizaciones de apoyo a los aliados que en realidad funcionaban de portada "destinadas a la difusión de las teorías comunistas". En las redadas, además de apresar a más de una centena de personas vinculadas al mundo de la izquierda y ser prolijamente publicados sus nombres en los periódicos, se secuestró una gran cantidad de libros, panfletos, carnets de afiliación, manifiestos y fotografías que serían usados para establecer la relación entre los comunistas

\footnotetext{
${ }^{27}$ Diario El Censor, Gualeguaychú, 07/07/1943.

${ }^{28}$ El Censor, 13/07/1943 y 15/07/1943.

${ }^{29}$ Lozza, Arturo: Brisas y tremolinas, Buenos Aires, Ediciones Yuquerí, 1982, p. 68-74.

${ }^{30}$ El Censor, 25/08/1943.
} 
y los políticos del régimen depuesto: “destapando el maridaje comunista-radical” declaraba un periódico conservador. ${ }^{31}$

Fue por esos días que Juan Balsechi recobraba la libertad. El día 14 de julio, después de veinticuatro días presos, fue puesto en libertad, las autoridades informaron que:

Efectivamente el llamado Juan Balsechi, fue recibido en esta Repartición el día 20 del mes de junio ppdo, remitido por el Encargado Provisional del Gobierno de la Provincia, General de Brigada Juan Carlos Sanguinetti Comandante de la 3ra División del Ejército.- Como de toda la actuación del nombrado, se desprende fehacientemente que sus actividades son puramente sindicales, el suscripto dispuso su libertad el día 12 del actual. $^{32}$

La nota continúa con una descripción pormenorizada de la actividad político sindical del implicado, se destacaba su "labor netamente sindicalista, exenta de ideologías extrañas a nuestros ambiente y luchando contra las mismas en forma permanente." La conciencia sindical-reformista de Balsechi lo salvaría esta vez.

Luego de aquel primer golpe a las organizaciones obreras y a los dirigentes, el gobierno tuvo una permanente vigilancia de los grupos sindicales. En octubre de 1943, con motivo de los 25 años del Despertar del Obrero (panadería cooperativa de los sindicalistas de Concepción del Uruguay), el jefe de la Policía de aquella ciudad se hizo presente. En su discurso destacó las medidas del gobierno de facto en materia de salarios mínimos, alquileres y artículos de primera necesidad, para finalizar diciendo:

os pido como argentinos que queréis vuestra Patria ¡ Ir a trabajar tranquilamente! Sin ese escuchar intrigas, ni expresiones malevolentes. Los odios y los rencores no restañan las heridas ni corrigen el mal. Vivamos todos unidos laborando para una Argentina fuerte y grande y gritemos desde el fondo de nuestro pecho, con orgullo ¡Viva la Patria! ${ }^{33}$

En tanto la política represiva del régimen no volvió a salir a superficie hasta abril de 1944, cuando asumió el nuevo interventor, el Teniente Coronel Carlos Zavalla, quien era acusado de antisemitismo y definido como un nacionalista duro dentro del elenco militar. ${ }^{34}$ Los sucesos relatados a continuación, dan cuenta de los motivos para esas opiniones. A

\footnotetext{
${ }^{31}$ El Entre Ríos, 17/07/1943.

${ }^{32}$ Nota interna del SubJefe de la Policía Federal, Teniente Coronel (R) José Allende al Ministro del Interior, Coronel Alberto Gilbert, Buenos Aires, 14 de Julio de 1943, en Ar-AGN. DAI. MI. COA. SCR.CAJA N7, DOC.82.

${ }^{33}$ La Juventud, Concepción del Uruguay, 19/10/1943.

${ }^{34}$ Rouquié, Alain: Poder militar y sociedad política en la Argentina, 1943-1973, Buenos Aires, Emecé Editores, 1982, Tomo 2, p.46.
} 
fines de abril, El Diario, prensa de la capital provincial vinculada al partido radical reproducía la siguiente información:

El interventor del Consejo Nacional de Educación ha confesado su propósito de seleccionar y sanear al personal que imparte la enseñanza a los niños, en las escuelas de su dependencia. A ese designio responder la cesantía de varios maestros a quienes se les atribuye la profesión de doctrinas contrarias a la nacionalidad y, desde luego, a su constitución y a sus instituciones republicanas y democráticas. (...)Hasta ahora la medida comprende a personas de tendencias izquierdistas cuando no comunistas, según se consigna en las respectivas resoluciones. Y decimos hasta ahora porque no ha de pasar inadvertido a su ojo vigilante que los malos maestros no se encuentran concentran concentrados en un solo y único sector ideológico por lo que, lógicamente, es de suponer que sus disposiciones comprenderán, en lo sucesivo, a quienes, desde otro ángulo conspiran contra la unidad espiritual de la Nación con sus prejuicios raciales y religiosos y contra la estabilidad de las instituciones. Nos estamos refiriendo, desde luego, a esa afloración de elementos nazifascistas... ${ }^{35}$

El comentario de El Diario parece ser una precaución de los hechos posteriores. En mayo se reglamentó la aplicación de la ley de educación religiosa, que obligaba a la enseñanza confesional dentro de las escuelas bajo el control de los párrocos locales. (El Entre Ríos, 10/05/1944.) También, días más tardes, el 14 de mayo, se clausura El Diario, en el marco de la aplicación de la ley que prohibía las actividades políticas críticas del régimen militar y enseguida se lo vinculó con actividades comunistas, afirmando que en el interior del local del medio informativo se había encontrado “...folletos, libros y panfletos de propaganda roja y subversiva, así como leyendas en las paredes con vivas al partido comunista, a los judíos y Stalin". 36

En paralelo, comenzó una persecución contra maestros de origen judío que fueron desvinculados de sus tareas y las escuelas hebreas cerradas. Si bien la los interventores habían atacado a la comunidad judía desde los primeros tiempos del golpe prohibiendo la faena ritual y la enseñanza del hebreo, a partir de 1944 comenzó a desarrollarse lo que Daniel Lvovich llamó “antisemitismo estatal". En el momento más profundo de las cesantías, durante agosto, las suspensiones alcanzaban a 122 docentes, con el argumento de ser judíos, faltos de patriotismo y simpatizantes del comunismo. ${ }^{37}$ Se logró revertir las

\footnotetext{
${ }^{35}$ El Diario, 26/04/1944.

${ }^{36}$ El Entre Ríos, 27/05/1944, 15/06/1944.

${ }^{37}$ Lvovich, Daniel: Nacionalismo y antisemitismo en la Argentina, Buenos Aires, Vergara, 2003, p. 535. Argachá, Celomar \& Busiello, Orlando: Nazismo y otros extremismos en Entre Ríos, Concepción del Uruguay, Yusty, 2013, p. 250-257.
} 
cesantías con ayuda de la Federación del Magisterio Entrerriano y la Delegación de Asociaciones Israelitas Argentinas (DAIA) cuando asumió el nuevo interventor, José Humberto Sosa Molina en septiembre de ese mismo año, lo que precipitó la salida del anterior interventor e intentó recuperar el apoyo y la simpatía para la revolución. ${ }^{38}$ También durante 1944 la Unión Obrera Departamental de Concepción del Uruguay es nuevamente intervenida. Son apresados tres dirigentes, Juan Balsechi entre ellos. Luego de dos meses de cárcel en Paraná y de gestionar su liberación, Balsechi debe exiliarse en la ciudad uruguaya de Paysandú, condición para su libertad. ${ }^{39}$

El año 1945 comenzaba en la misma tónica. El 5 de enero fueron apresados y puestos a disponibilidad dos:

\begin{abstract}
obreros catalogados como dirigentes comunistas JOSE TOMÁS CERRUDO y ADAN VICENTE DOME o ADAN JACOB, respectivamente, a raíz de haber promovido una huelga entre los obreros de la Base Aérea Militar "General Justo José de Urquiza" de esta capital; huelga esta que fue declarada ilegal por la Delegación Regional de Trabajo y Previsión y agregaba- Desde entonces dichos obreros se hallan detenidos, tal como lo disponen los citados decretos; pero últimamente me ha visto en la precisión de estudiar varios petitorios de sus compañeros de trabajadores, en los que solicitan su libertad. Mientras me he considerado tales peticiones, para elevar mi informe al respecto, ha venido aumentando el interés de los obreros por gestionar la libertad de los citados dirigentes, al punto de que puede presumirse que llegue hace ser un fuerte movimiento de opinión. Por eso considero que será conveniente disponer que la actual detención, de Cerrudo y Dome o Jacob, se cambie por la interdicción de residir en territorio entrerriano, con lo que se les devolvería su libertad, pero evitando al mismo tiempo su posible acción disolvente en el medio en que han actuado. ${ }^{40}$
\end{abstract}

Por el apoyo de sus compañeros obtendrán la libertad en el mes de abril, pero se les prhibió permanecer en el territorio entrerriano. ${ }^{41}$ En febrero de 1945 son apresados en Concepción del Uruguay y Basavilbaso a militantes vinculados al Partido Comunista y a la UCR:

\footnotetext{
${ }^{38}$ López, Celia: “La Revolución de 1943 en Entre Ríos: un claro caso de discriminación y racismo. Intervención Zavalla.” En Revista del Departamento de Investigación, ENSMM, Año II, N², Concepción del Uruguay, 2000, p.71.

${ }^{39}$ Arnaiz, Op. cit., p.110. Y Gilbert \& Balsechi, Op. cit., p.100.

${ }^{40}$ Nota telegráfica del Interventor Federal Gral de Brigada Humberto Sosa Molina al Ministro del Interior interino Contraalmirante Alberto Teisaire, Paraná, 31 de marzo de 1945, en Ar-AGN. DAI. MI. COA. SCR. Caja 32, Doc. 357.

${ }^{41}$ Poder Ejecutivo Nacional. Decreto Presidencial, Buenos Aires, 10 de abril de 1945, en Ar-AGN. DAI. MI. COA. SCR. Caja 32, Doc. 357.
} 
Conforme circular 320 del 6 de septiembre de 1944 comunico a VE que a raíz averiguaciones efectuadas en departamento Uruguay han sido detenidos por intervenir en distribución panfletos comunistas los señores Rosendo Domínguez, Albañil, Uruguayo, José Vaimberg, peluquero y Juan José Bruno, médico del Hospital Beneficencia Concepción del Uruguay.- Estos detenidos quedan en la policía Central de Paraná a disposición del PE nacional.- También ha sido detenido el menor de 17 años Dionisio Silvano Valdivia estudiante por igual motivo y en atención su edad ha quedado bajo tutela patronato de menores. ${ }^{42}$

La detención del médico llevó a una intervención de sus colegas y hasta de los miembros del sindicato portuario que reclamaron por su liberación al ministro del Interior. El 14 de febrero fueron puestos en libertad el médico y el menor. Indicando que su participación se limitaba a la distribución de un periódico llamado "El Constitucional", asimismo, se disponía de la liberación del menor bajo la tutela estricta de sus padres. ${ }^{43}$ En cuanto a los otros tres presos:

las conclusiones del sumario son terminantes en su contra, pues de sus propias declaraciones y de las demás pruebas se concluye que son elementos comunistas y subversivos. Opino, en consecuencia, que estas tres personas deben permanecer detenidas a disposición del Poder Ejecutivo Nacional

También el telegrama informa que por averiguaciones fueron apresados otros tres jóvenes vinculados al Movimiento Unitario de la Juventud Argentina (U.J.A.) organización colateral de la Federación Juvenil Comunista, a la que pertenecía el menor antes detenido. ${ }^{44}$ En paralelo a estos sucesos, en la localidad de Crespo, departamento de Paraná, el día 8 de febrero, se realizaban allanamientos en la casa de un conscripto que repartía panfletos comunistas que llamaban a la lucha contra la dictadura "GOUnazi" y denunciaba el encarecimiento de la vida, firmados por el Comité Central del PC de la Capital Federal. También poseía algunos libros comunistas. ${ }^{45}$ Por esto fueron apresados cuatro personas. Informaba Sosa Molina:

\footnotetext{
${ }^{42}$ Nota telegráfica del Interventor Federal Gral. de Brigada Humberto Sosa Molina al Ministro del Interior interino Contraalmirante Alberto Teisaire, Paraná, 02 de febrero de 1945, en Ar-AGN. DAI. MI. COA. SCR. Caja 30, Doc. 134.

${ }^{43}$ República Argentina, Ministerio del Interior. Exp. 7748-C-1945, Paraná, 14 de Febrero de 1945, en ArAGN. DAI. MI. COA. SCR. Caja 30, Doc. 134.

${ }^{44}$ Nota telegráfica del Interventor Federal Gral. de Brigada Humberto Sosa Molina al Ministro del Interior interino Contraalmirante Alberto Teisaire, Paraná, 16 de febrero de 1945, en Ar-AGN. DAI. MI. COA. SCR. Caja 31, Doc. 181.

${ }^{45}$ Nota telegráfica del Jefe de Policía de la Provincia Luis Italo Cavalli al Ministro de Gobierno, Coronel Ricardo Mendióroz, Paraná, 08 de febrero de 1945, en Ar-AGN. DAI. MI. COA. SCR. Caja 31, Doc. 161.
} 
Se ha comprobado, hasta este momento que quien llevó la propaganda a Villa Crespo fue Gerónimo Agustín Zaragoza, ciudadano que se halla prestando servicio militar en el $4^{\circ}$ de infantería con asiento en Montes Caseros (Pvcia. De Corrientes), por lo cual he dispuesto lo necesario para que dicho soldado compadezca al proceso de debe seguirle con este motivo. ${ }^{46}$

A partir de abril, el Interventor provincial solicita información a las autoridades nacionales para resolver la situación de los apresados por motivos políticos. Para aquella época eran nueve los presos. Los motivos por los que habían sido encarcelados eran básicamente la distribución de panfletos y tareas de agitación y, los dos promotores de la huelga en la Base Aérea de Paraná. Cinco habían sido encarcelados en la unidad penal de Gualeguaychú y cuatro de ellos, en la ciudad de Buenos Aires. Todos fueron liberados con la imposibilidad de volver a la provincia de Entre Ríos por el Decreto Nº7948/45 del 17 de abril de 1945 . $^{47}$

Así se cerraba el ciclo de represiones selectivas provocadas por la denominada Revolución del 4 de Junio. En el complejo año 1945, con las manifestaciones de los sectores medios inconformes y la movilización del estudiantado, a pocos días del histórico 17 de octubre, se produjeron marchas de los estudiantes del Colegio Nacional de Concepción del Uruguay que terminaron con la represión de los mismos, a sablazos limpios según los periódicos, y con un saldo importante de detenidos. ${ }^{48}$ Llamativamente, los diarios locales no informan de los hechos.

Los días posteriores a los sucesos de la plaza de Mayo -el 17 de octubre-, se cambió de interventor - una vez más- y el lugar de Sosa Molina fue ocupado desde el 18 de octubre por Eduardo Frascheri López, hasta el llamado a elecciones y posterior paso del poder al primero gobernador peronista de la provincia, Héctor Maya.

\section{4-Conclusión.}

El golpe militar de 1943 será recordado más por su hijo -el peronismo- que por las medidas tomadas dentro del recorte temporal que ejerció el poder. Sin embargo, y sin

\footnotetext{
${ }^{46}$ Nota telegráfica del Interventor Federal Gral. de Brigada Humberto Sosa Molina al Ministro del Interior interino Contraalmirante Alberto Teisaire, Paraná, 09 de febrero de 1945, en Ar-AGN. DAI. MI. COA. SCR. Caja 31, Doc. 181.

${ }^{47}$ Nota del Interventor Federal Gral de Brigada Humberto Sosa Molina al Ministro del Interior interino Contraalmirante Alberto Teisaire, Paraná, 4 de abril de 1945, en Ar-AGN. DAI. MI. COA. SCR. Caja 32, Doc. 366.

${ }^{48}$ El Censor, 03/10/1945 y 05/10/1945.
} 
intenciones de acotar la caracterización de solo ser el camino de ascenso de Perón, podemos descubrir en su interior un programa ejecutado por un grupo de oficiales del Ejército, que buscaron grandilocuentemente "salvar a la Argentina del estado de anomia y descomposición política y social en que se encontraba". Dentro de sus principales tareas estuvo la represión del comunismo. Nombre que resultó excesivamente genérico, y englobó a militantes sindicalistas, comunistas propiamente dicho, incluso algunos radicales, sin olvidar el manto de desconfianza hacia la comunidad judía provincial.

Resulta interesante de la reconstrucción histórica que las prácticas de represión fueron ejercidas por todos los Interventores. En el rescate de los acontecimientos, encontramos que durante los primeros días de la Revolución, fue encarcelado el dirigente sindicalista Balsechi. Pronto, con la llegada del Interventor Ramírez, se dio la tarea de cerrar locales partidarios, denunciar la convivencia entre los radicales y los comunistas y, encarcelar más de una centena de militantes de diferentes extracciones políticas. Cuando Ramírez fue reemplazado por Zavalla, una nueva etapa se abrió. Posiblemente Zavalla sería el mejor candidato a "el más reaccionario". En una política de persecución hacía los comunistas, el periódico de la capital provincial que mantuvo un discurso levemente crítico al gobierno de facto, fue clausurado y finalmente, la imposición de la educación religiosa, el desplazamiento de docentes judíos, acusados de anti-patriotas y el cierre de los espacios de socialización religioso-cultural de esa colectividad se pusieron al orden del día. El malestar que generó su accionar, fue prontamente reemplazado por el General Sosa Molina, quién restituyó a los docentes pero se mantuvo la vigilancia contra los elementos comunistas que estaban en plena etapa de agitación. A quienes eran atrapados, se los encarcelaba y posteriormente, expulsaba de la provincia prohibiendo su vuelta.

Detrás de la represión, se esconden dos objetivos. Por un lado, la necesidad del gobierno de facto de afirmar su poder a través de prácticas coercitivas. Por otro, un modelo de defensa del orden capitalista, detrás de la ficción nacionalista y de la defensa de la patria, se ataca lo que no es estrictamente "argentino", es decir, subordinado al poder estatal y a su clase dominante. 


\section{Fuentes y bibliografía}

\section{Fuentes Inéditas.}

- Nota del Interventor Federal Gral de Brigada Humberto Sosa Molina al Ministro del Interior interino Contraalmirante Alberto Teisaire, Paraná, 4 de abril de 1945, en Argentina-Archivo General de la Nación. Departamento Archivo Intermedio, Ministerio del Interior, Comisión de Organización de Archivos. Secretos, confidenciales y reservados, Caja $\mathrm{N}^{\circ} 32$, Documento Reservado $366 .{ }^{49}$

- Nota interna del SubJefe de la Policía Federal, Teniente Coronel (R) José Allende al Ministro del Interior, Coronel Alberto Gilbert, Buenos Aires, 14 de Julio de 1943, en Ar-AGN. DAI. MI. COA. SCR.CAJA No7, DOC.82.

- Nota telegráfica del Secretario General de los trabajadores portuarios, Martiniano Gómez al Ministro del Interior interino Contraalmirante Alberto Teisaire, Concepción del Uruguay, 11 de febrero de 1945, en Ar-AGN. DAI. MI. COA. SCR. Caja 30, Doc. 134.

- Nota telegráfica del Interventor Federal Gral de Brigada Humberto Sosa Molina al Ministro del Interior interino Contraalmirante Alberto Teisaire, Paraná, 31 de marzo de 1945, en Ar-AGN. DAI. MI. COA. SCR. Caja 32, Doc. 357.

- Nota telegráfica del Interventor Federal Gral. de Brigada Humberto Sosa Molina al Ministro del Interior interino Contraalmirante Alberto Teisaire, Paraná, 02 de febrero de 1945, en Ar-AGN. DAI. MI. COA. SCR. Caja 30, Doc. 134.

- Nota telegráfica del Interventor Federal Gral. de Brigada Humberto Sosa Molina al Ministro del Interior interino Contraalmirante Alberto Teisaire, Paraná, 16 de febrero de 1945, en Ar-AGN. DAI. MI. COA. SCR. Caja 31, Doc. 181.

- Nota telegráfica del Interventor Federal Gral. de Brigada Humberto Sosa Molina al Ministro del Interior interino Contraalmirante Alberto Teisaire, Paraná, 09 de febrero de 1945, en Ar-AGN. DAI. MI. COA. SCR. Caja 31, Doc. 181.

- Nota telegráfica del Jefe de Policía de la Provincia Luis Italo Cavalli al Ministro de Gobierno, Coronel Ricardo Mendióroz, Paraná, 08 de febrero de 1945, en Ar-AGN. DAI. MI. COA. SCR. Caja 31, Doc. 161.

- Poder Ejecutivo Nacional. Decreto Presidencial, Buenos Aires, 10 de abril de 1945, en Ar-AGN. DAI. MI. COA. SCR. Caja 32, Doc. 357.

- República Argentina, Ministerio del Interior. Exp. 7748-C-1945, Paraná, 14 de Febrero de 1945, en Ar-AGN. DAI. MI. COA. SCR. Caja 30, Doc. 134.

- Telegrama del Interventor Federal Interino, General de Brigada Juan Carlos Sanguinetti al Ministro del Interior, Coronel Alberto Gilbert, Paraná, 20/06/1943 en en Ar-AGN. DAI. MI. COA. SCR. Caja 7, Doc. 82.

\section{Diarios y periódicos.}

- Diario El Censor, Gualeguaychú, 1943-1945.

\footnotetext{
${ }^{49}$ En adelante: Ar-AGN. DAI. MI. COA. SCR.CAJA No, DOC.
} 
- Diario El Diario, Paraná, 1943-1945.

- Diario La Acción, Paraná, 1943.

- Diario La Juventud, Concepción del Uruguay, 1945.

- Periódico Actualidad, Nogoyá, 1943.

- Periódico El Entre Ríos, Colón, 1943-1944.

- Periódico Unión Sindical, Órgano de la Unión Sindical Argentina, Buenos Aires, 1943.

\section{Bibliografía.}

- Argachá, Celomar \& Busiello, Orlando: Nazismo y otros extremismos en Entre Ríos, Concepción del Uruguay, Yusty, 2013.

- Arnaiz, María del Carmen: "Un Oasis en el desierto. La Unión Obrera Departamental de Concepción del Uruguay" en Di Tella, Torcuato: Sindicatos como los de antes...Buenos Aires, Biblos, 1993.

- Campione, Daniel: Orígenes estatales del peronismo, Buenos Aires, Miño y Dávila, 2007.

- Del Campo, Hugo: Sindicalismo y peronismo, Buenos Aires, Siglo XXI Editores, 2005.

- Doyon, Louis: Perón y los trabajadores: los orígenes del sindicalismo peronista, 1943-1955, Buenos Aires, Siglo XXI editores, 2006.

- Fayt, Carlos: La Naturaleza del peronismo, Buenos Aires, Viracocha, 1967.

- Germani, Gino: Política y sociedad en una época de transición, Buenos Aires, Paidos, 1962.

- Gianello, Leoncio: Historia de Entre Ríos (1520-1910), Paraná, Ministerio de Educación, 1951.

- Gilbert, Isidoro \& Balsechi, Elisa: Voces del sindicalismo entrerriano: Memorias de la Unión Obrera Departamental de Concepción del Uruguay, 1918-1943, Buenos Aires, Ediciones del Zorrito, 2008.

- Gramsci, Antonio: Notas sobre Maquiavelo, sobre la política y sobre el Estado moderno, Buenos Aires, Ed. Nueva Visión, 2003.

- Horowitz, Joel: Los sindicatos, el Estado y el surgimiento de Perón, 1930-1946, Buenos Aires, Universidad Nacional de Tres de Febrero, 2004.

- Kabat, Marina: "El peronismo, los orígenes de la SIDE y de la 'maldita policía'" en Razón y Revolución, Segunda Época, №29, 1er. Trimestre, Buenos Aires.

- López, Celia: "La Revolución de 1943 en Entre Ríos: un claro caso de discriminación y racismo. Intervención Zavalla." En Revista del Departamento de Investigación, ENSMM, Año II, N², Concepción del Uruguay, 2000.

- Lozza, Arturo: Brisas y tremolinas, Buenos Aires, Ediciones Yuquerí, 1982. 
- Lvovich, Daniel: Nacionalismo y antisemitismo en la Argentina, Buenos Aires, Vergara, 2003.

- Marx, Carlos: "El dieciocho brumario de Luis Bonaparte" en Marx, Carlos \& Engels, Federico: Obras escogidas en dos tomos, Moscú, Editorial Progreso, 1955, Tomo I.

- Matsushita, Hiroshi: Movimiento obrero argentino, 1930-1945, Buenos Aires, Ediciones RyR, 2014.

- Mier, Eugenio: "Nota aclaratoria" Perón, Juan Domingo: en Obras Completas, Buenos Aires, Fundación proUniversidad de la Producción y del Trabajo, 1997, Tomo 6.

- Perón, Juan Domingo: “A los trabajadores de Concepción del Uruguay” en Obras Completas, Buenos Aires, Fundación proUniversidad de la Producción y del Trabajo, Tomo 6, 1997.

- Potash, Robert: El ejército y la política en la Argentina, Buenos Aires, Hyspamerica, 1985, Tomo I.

- Potash, Robert: Perón y el G.O.U. Los documentos de una Logia Secreta, Buenos Aires, Editorial Sudamericana, 1984.

- Reula Filiberto: Historia de Entre Ríos, Santa Fe, Ed. Castellví, 1971, Tomo III.

- Romero, José Luis: Las ideas políticas en Argentina, Buenos Aires, FCE, 2005. [Primera edición 1956]

- Rouquié, Alain: Poder militar y sociedad política en la Argentina, 1943-1973, Buenos Aires, Emecé Editores, 1982, Tomo 2.

- Torre, Juan Carlos: La vieja guardia sindical y Perón, Buenos Aires, Ediciones RyR, 2011. 